\title{
Hypokalemic paralysis associated with cystic disease of the kidney: case report
}

\author{
Champika SSSK Gamakaranage ${ }^{1}$, Chaturaka Rodrigo ${ }^{2}$, Saroj Jayasinghe ${ }^{2}$ and Senaka Rajapakse ${ }^{2^{*}}$
}

\begin{abstract}
Background: Severe hypokalemia is known to cause muscle paralysis, and renal tubular acidosis is a recognized cause. Cystic disease of the kidney is associated with severe hypokalemia.

Case presentation: We report a 33-year-old male patient who presented with generalized limb weakness caused by severe hypokalemia due to renal tubular acidosis, who was found to have renal medullary cysts.

Conclusion: The association of cystic renal disease with hypokalemia, and the possible pathophysiological basis of the development of renal cysts in patients with severe hypokalemia, are discussed.
\end{abstract}

Keywords: hypokalemia renal tubular acidosis, medullary cystic kidney, renal cysts

\section{Background}

Severe hypokalemia is known to result in muscle paralysis [1], and renal tubular acidosis (RTA) is a recognized cause $[2,3]$. RTA is a condition where acid excretion by the kidneys is impaired, resulting in systemic acidosis. The classical type of RTA is the 'distal' or Type 1. Renal potassium loss occurs in Type 1 RTA, which results in hypokalemia [4]. There are numerous causes and associations of Type 1 RTA, and the condition can be hereditary, congenital, acquired or idiopathic [4]. RTA and severe hypokalemia have been associated with medullary sponge kidney [5] and other cystic conditions of the kidney. Nephrocalcinosis is also often associated [4]. The reason for formation of renal cysts, either in the classical form of medullary sponge kidney, or other variants, is unclear. We report a patient who presented with severe hypokalemia due to renal tubular acidosis who was found to have cystic renal disease, and discuss the possible pathogenesis of cyst formation in the kidney.

\section{Case presentation}

A 33-year-old male farmer presented with a history of excessive thirst, weight loss, and increased urine output over the preceding two months. He then developed generalized body weakness, associated with vomiting which

\footnotetext{
* Correspondence: senaka.ucfm@gmail.com

${ }^{2}$ Department of Clinical Medicine, Faculty of Medicine, University of

Colombo, Colombo 08, Sri Lanka

Full list of author information is available at the end of the article
}

occurred 3-5 times a day, over the past 2 weeks prior to admission. The weakness, which was predominantly in the limbs and the neck, worsened over the course of the next two weeks, and on admission he was bed bound. At the time of presentation his motor power was grade 2 in all limbs (unable to move against gravity, movement possible with gravity eliminated [6]), and he was unable to move his neck. The limbs were hypotonic with absent reflexes, and muscle tenderness was present. However, there was no respiratory difficulty, diplopia or dysarthria. He retained his bladder and bowel control. His height was $156 \mathrm{~cm}$ and weight was $52 \mathrm{~kg}$ (BMI of $\left.21.4 \mathrm{~kg} / \mathrm{m}^{2}\right)$. Cardiovascular, respiratory and abdominal examination did not reveal any abnormalities. While this acute episode was dramatic in onset, it was also noted that over the last 2 years he had intermittently complained of ill health, pain in the legs, backache and body pains, and had been off work frequently.

He had no history of any other significant medical or psychiatric comorbidities. There was no other significant illness that required hospitalization or long term treatment during his neonatal period or childhood. He had not been on any long term medication or indigenous medicine. There was no significant family history. He had not used any addictive substances.

His serum potassium level was less than $1 \mathrm{mEq} / \mathrm{l}$ (3.5-5.1) at that time of peak paralysis; serum sodium was $135 \mathrm{mEq} / \mathrm{l}$ (135-148), chloride $96 \mathrm{mEq} / \mathrm{l}$ (95-105). The electrocardiogram at this stage showed flattened $\mathrm{P}$

\section{Ciomed Central}


waves, and $U$ waves. His serum creatinine readings were between $80-120 \mu \mathrm{mol} / \mathrm{l}(60-120)$ and the random blood sugar was $102 \mathrm{mg} / \mathrm{dl}(<200)$. The estimated glomerular filtration rate (eGFR) was between $64-90 \mathrm{ml} / \mathrm{min} / \mathrm{m}^{2}$ based on these values. He had neutrophil leucocytosis (total count 18,800 cells/ $\mu$ l with $90 \%$ neutrophils). The hemoglobin and platelet counts were within the reference range.

The priority at this stage was correction of his serum potassium. With intravenous replacement of potassium, the muscle power and the overall clinical condition of the patient improved rapidly.

We investigated him for a cause of hypokalemia. The main reasons for hypokalemia are excessive losses (renal or gastrointestinal loss) or redistribution within body compartments. This patient had vomiting and polyuria, hence loss through the gastrointestinal tract or kidneys was considered. Given the protracted history for 2 years, associated with polyuria, polydipsia and weight loss, we considered renal potassium loss to be more likely. Spot urine analysis showed urinary potassium of $24 \mathrm{mEq} / \mathrm{l}$ (13-62) and sodium of $120 \mathrm{mEq} / \mathrm{l}$. The patient had a 24 hour urine volume of $3500 \mathrm{ml}$, and despite severe hypokalemia he was losing potassium in his urine. A subsequent 24-hour urinary potassium level confirmed an abnormally excessive urinary potassium loss of $80 \mathrm{mmol} / 24$ hours despite severe hypokalemia (reference range: $40-100)$.

Urinalysis revealed a urine $\mathrm{pH}$ of 6.5 and 7.5 on two occasions. There were a few calcium oxalate crystals and 2-4 red cells per high power field. There was also a mild hypercalciuria, with a 24-hour urinary calcium excretion of $0.134 \mathrm{mmol} / \mathrm{kg}$ (upper limit $0.1 \mathrm{mmol} / \mathrm{kg} /$ day). The rest his urinalysis was normal and there was no glycosuria or proteinuria.

At the time of peak paralysis, the arterial blood gas showed a $\mathrm{pH}$ of 7.45 (7.35-7.45), $\mathrm{pCO}_{2}$ of $22.4 \mathrm{mmHg}$ (36-44), $\mathrm{pO}_{2}$ of $129 \mathrm{mmHg}$ (80-100), Oxygen saturation of $99 \%$, Bicarbonate of $15.6 \mathrm{mmol} / \mathrm{l}$ (22-28), and a base excess of $(-) 8.6 \mathrm{mEq} / \mathrm{l}$. This picture was suggestive of a compensated metabolic acidosis. He was admitted to the intensive care unit and daily arterial blood gases were performed. These continued to show metabolic acidosis ( $\mathrm{pH}$ : 7.207.25). Plasma anion gap was $12.2 \mathrm{mEq} / \mathrm{l}(10-14)$. Thus this patient had normotensive hypokalemia with a normal anion gap (hyperchloremic) metabolic acidosis, and persistently alkaline urine (his urine $\mathrm{pH}$ was $>5.5$ despite metabolic acidosis). The urine anion gap was positive $\left(\mathrm{U}_{\mathrm{Na}}\right.$ $120+\mathrm{U}_{\mathrm{K}} 24-\mathrm{U}_{\mathrm{Cl}} 116=28$ ). These findings are compatible with renal tubular acidosis (RTA), most likely distal/type 1 RTA (dRTA 1).

While further investigating for a cause for the RTA, renal ultrasound showed bilaterally enlarged kidneys with multiple cysts of varying sizes. Cortical echogenicity was increased with altered cortico-medullary demarcation.

This was investigated further with a computed tomography-intravenous urogram (CT IVU) which revealed enlarged (right $-125 \mathrm{~mm}$, left $-123 \mathrm{~mm}$ ) kidneys with variable sized multiple thin walled medullary cysts with no septae in both kidneys (figure 1). The largest cyst measured $30 \mathrm{~mm} \times 25 \mathrm{~mm}$. Fine calcified foci of 1-2 mm were seen in cortices of both kidneys. Similar cysts were not observed in the liver, pancreas or in any other solid organ.

The creatine kinase level in this patient was high (initially $704 \mathrm{IU} / \mathrm{l}$ and increased to $1262 \mathrm{IU} / \mathrm{L}$ subsequently, reference range: 60-300) probably due to rhabdomyolysis associated with hypokalemia and RTA [5,7], although this did not result in acute kidney injury (AKI).

Liver transaminases were elevated [AST -151 U/l (10-40) and ALT - $208 \mathrm{U} / \mathrm{l}$ (10-40), which could be due to many reasons, related or unrelated to renal tubular acidosis. The possibility of Wilsons disease was considered as it may also present as renal tubular acidosis [7]. However, ophthalmological assessment excluded Kaiser-Fleisher (KF) rings in this patient. Chronic active hepatitis is also known to be associated with renal tubular acidosis and hypokalemia [8].

\section{Conclusions}

The most common causes of hypokalemic paralysis include thyrotoxic periodic paralysis, renal tubular acidosis, and hypokalemic periodic paralysis [1]. Cystic disease of the kidney has long been associated with hypokalemia and sometimes with renal tubular acidosis. One of the classical associations between cystic

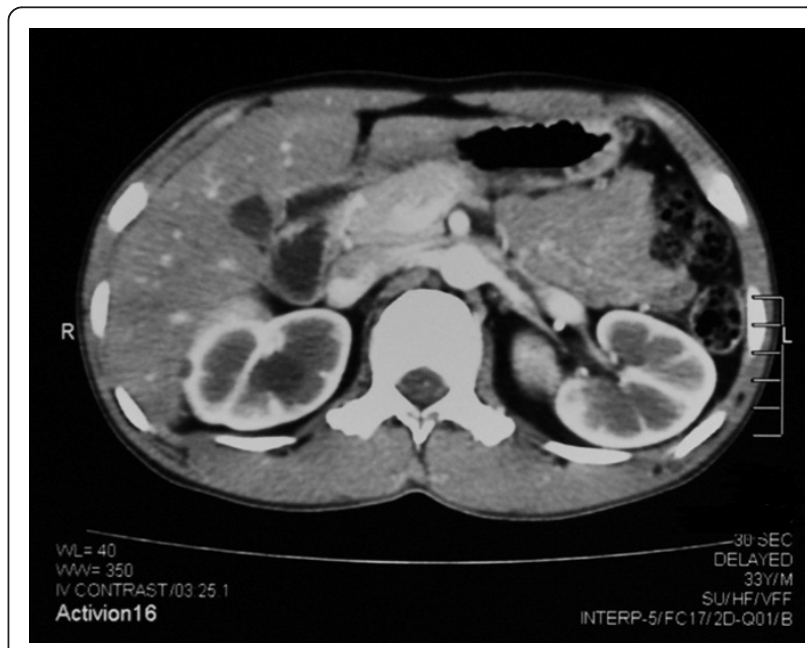

Figure 1 Contrast-enhanced CT scan abdomen showing multiple medullary cysts in both kidneys. 
disease of the kidney, renal tubular acidosis and hypokalemia is medullary sponge kidney (MSK) [5]. MSK is a poorly understood disease [9]. Patients are usually asymptomatic; those with symptoms usually present with renal or ureteric colic, haematuria and polyuria. Often, a patient with a medullary sponge kidney may undergo decades of suffering with infections and pain before the diagnosis is made. When a diagnosis is made, it is more likely to be an incidental finding. The changes seen in MSK are thought to reflect a developmental or congenital abnormality, although the true underlying defect is unknown [10]. There is no firm evidence of genetic transmission, yet there are some families that appear to show an autosomal dominant inheritance [5,11]. Medullary sponge kidney is known to be associated with hypokalemia, nephrocalcinosis and RTA [5,12,13].

The diagnosis of MSK is typically made by intravenous urogram $[10,14]$. It is characterized by ectasia of the papillary collecting ducts in the medulla. These converge at the tips of pyramids where all or many of the pyramids are involved. On intravenous urogram these cystic dilatations lead to the appearance of a 'brush' radiating outward from some or all of the calyces ('bouquet of flowers' appearance) due to collection of contrast in the dilated ducts [15]. Enlargement of the pyramids and intra-ductal concretions are also often seen. Calcium stones, if present, are typically small and, almost pathognomonically, occur in clusters limited to the affected calyces. MSK is essentially a radiological diagnosis, with numerous reported associations. The long term prognosis is excellent, although obstructive uropathy due to calculi can result in transient reductions in glomerular filtration rate. Rarely calculi may cause recurrent obstruction and infection in which can progress to chronic kidney disease.

In this patient, renal tubular acidosis resulting in severe hypokalemia appeared to be the primary diagnosis to explain his clinical symptoms. Although renal cysts were identified on radiological imaging, the classical features of MSK were not found (see above). Hence, other causes of cystic disease were also considered. The cysts were medullary in location, and thus not in keeping with polycystic kidney disease.

Torres et al [16] had suggested that, at least in a proportion of patients, renal cyst formation may be a result of severe hypokalemia rather than a simple association. The study compared patients with aldosteronism and hypokalemia with controls with essential hypertension. Renal cyst formation was significantly more common in patients with hypokalemia and aldosteronism, and the extent of cyst development correlated with lower potassium levels. Furthermore, removal of the adrenal adenomas resulted in regression of the cysts which also corresponded to the normalization of serum potassium levels.
Cyst formation is thought to occur due to enhanced growth and proliferation of the epithelial cells lining the cysts [17]. Under experimental conditions, hypokalemia stimulates protein synthesis and cell division $[18,19]$. This evidence supports the postulate that severe hypokalemia promotes the formation of renal cysts. We suggest that the renal cysts detected in this patient developed as a result of profound hypokalemia, and is neither a simple association, nor the primary abnormality resulting in RTA and hypokalemia. We also propose that hypokalemia induced tissue proliferation may, at least in some cases, be the etiological factor for the often described association of renal tubular acidosis and cystic disease of the kidney. If this were the case, it is probable possible that long term correction of hypokalemia would result in regression of the cysts. We intend to follow this patient up to determine this.

\section{Consent}

Written informed consent was obtained from the patient for this case to be published.

\section{Abbreviations}

MSK: Medullary Sponge Kidney; RTA: Renal Tubular Acidosis; CT-IVU: Computerised tomography-intravenous urogram; BMI: body mass index

\section{Acknowledgements}

We gratefully acknowledge Mr Amal Ranawaka, Photography Technologist, Audiovisual Unit, Faculty of Medicine, University of Colombo for his help with the images.

\section{Author details}

${ }^{1}$ University Medical Unit, National Hospital, Colombo 08, Sri Lanka. ${ }^{2}$ Department of Clinical Medicine, Faculty of Medicine, University of Colombo, Colombo 08, Sri Lanka.

\section{Authors' contributions}

CSSKG, CR and SR researched the background literature on the case and wrote the first draft. SJ contributed towards the discussions and analysis of the case. SR wrote the final draft. All authors reviewed the final manuscript.

\section{Authors' information}

CSSKG (MBBS) is registrar in general medicine in the University Medical Unit, National Hospital, Colombo, Sri Lanka. CR(MBBS) is Lecturer in Medicine, and SJ(MD, FRCP, MD) and SR(MD, FRCP Edin, FACP) are Professors in Medicine, in the Department of Clinical Medicine, Faculty of Medicine, University of Colombo, Sri Lanka.

\section{Competing interests}

The authors declare that they have no competing interests.

Received: 20 January 2011 Accepted: 18 April 2011

Published: 18 April 2011

\section{References}

1. Stedwell RE, Allen KM, Binder LS: Hypokalemic paralyses: a review of the etiologies, pathophysiology, presentation, and therapy. Am J Emerg Med 1992, 10(2):143-148.

2. River GL, Kushner DS, Armstrong SH Jr, Dubin A, Slodki SJ, Cutting HO: Renal tubular acidosis with hypokalemia and muscular paralysis. Metabolism 1960, 9:1118-1132.

3. Rowbottom SJ, Ray DC, Brown DT: Hypokalemic paralysis associated with renal tubular acidosis. Crit Care Med 1987, 15(11):1067-1068. 
4. Caruana RJ, Buckalew VM Jr: The syndrome of distal (type 1) renal tubular acidosis. Clinical and laboratory findings in 58 cases. Medicine (Baltimore) 1988, 67(2):84-99.

5. Jayasinghe KS, Mendis BL, Mohideen R, Ekanayake R, Sheriff MH, Dharmadasa K: Medullary sponge kidney presenting with hypokalaemic paralysis. Postgrad Med J 1984, 60(702):303-304.

6. Olney RK, Aminoff MJ: Weakness, myalgias, disorders of movement and imbalance. In Harrison's Principles of Internal Medicine. Volume 1. 15 edition. Edited by: Braunwald F, Kasper, Hauser, Longo, Jameson. New York: McGraw-Hill; 2001:118-121.

7. Chu CC, Huang CC, Chu NS: Recurrent hypokalemic muscle weakness as an initial manifestation of Wilson's disease. Nephron 1996, 73(3):477-479.

8. Koul PA, Saleem SM: Chronic active hepatitis with renal tubular acidosis presenting as hypokalemic periodic paralysis with respiratory failure. Acta Paediatr 1992, 81(6-7):568-569.

9. Pritchard MJ: Medullary sponge kidney: causes and treatments. $\mathrm{Br} J$ Nurs 2010, 19(15):972-976.

10. Yendt ER: Medullary Sponge Kidney. In Diseases of the Kidney. 5 edition. Edited by: Schrier RW. Boston: Little, Brown; 1993:525-532.

11. Goldman SH, Walker SR, Merigan TC Jr, Gardner KD Jr, Bull JM: Hereditary occurrence of cystic disease of the renal medulla. N Engl J Med 1966, 274(18):984-992.

12. Kasap B, Soylu A, Oren O, Turkmen M, Kavukcu S: Medullary sponge kidney associated with distal renal tubular acidosis in a 5 -year-old girl. Eur J Pediatr 2006, 165(9):648-651.

13. Carboni I, Andreucci E, Caruso MR, Ciccone R, Zuffardi O, Genuardi M, Pela I, Giglio S: Medullary sponge kidney associated with primary distal renal tubular acidosis and mutations of the H+-ATPase genes. Nephrol Dial Transplant 2009, 24(9):2734-2738.

14. Levine E, Hartman DS, Meilstrup JW, Van Slyke MA, Edgar KA, Barth JC: Current concepts and controversies in imaging of renal cystic diseases. Urol Clin North Am 1997, 24(3):523-543.

15. Bisceglia M, Galliani CA, Senger C, Stallone C, Sessa A: Renal cystic diseases: a review. Adv Anat Pathol 2006, 13(1):26-56.

16. Torres VE, Young WF Jr, Offord KP, Hattery RR: Association of hypokalemia, aldosteronism, and renal cysts. N Engl J Med 1990, 322(6):345-351.

17. Grantham JJ: Polycystic kidney disease-an old problem in a new context. N Engl J Med 1988, 319(14):944-946.

18. Walsh-Reitz MM, Toback FG: Kidney epithelial cell growth is stimulated by lowering extracellular potassium concentration. Am J Physiol 1983, 244(5): C429-432.

19. Novak-Hofer I, Kung W, Eppenberger U: Role of extracellular electrolytes in the activation of ribosomal protein $\mathbf{S 6}$ kinase by epidermal growth factor, insulin-like growth factor 1, and insulin in ZR-75-1 cells. J Cell Biol 1988, 106(2):395-401

\section{Pre-publication history}

The pre-publication history for this paper can be accessed here: http://www.biomedcentral.com/1471-2369/12/16/prepub

doi:10.1186/1471-2369-12-16

Cite this article as: Gamakaranage et al:: Hypokalemic paralysis associated with cystic disease of the kidney: case report. BMC Nephrology 2011 12:16.

\section{Submit your next manuscript to BioMed Central and take full advantage of:}

- Convenient online submission

- Thorough peer review

- No space constraints or color figure charges

- Immediate publication on acceptance

- Inclusion in PubMed, CAS, Scopus and Google Scholar

- Research which is freely available for redistribution

Submit your manuscript at www.biomedcentral.com/submit
C Biomed Central 